\title{
Normal pregnancy and successful delivery in myophosphorylase deficiency (McArdle's disease)
}

\author{
PETER COCHRANE AND BRIAN ALDERMAN \\ From Walton Hospital and the Maternity Hospital, Liverpool
}

SUMMARY The progress in pregnancy of a female with myophosphorylase deficiency (McArdle's disease) is described. In spite of the increased muscular effort expended, both pregnancy and labour were normal and the muscle symptoms unchanged, suggesting that compensatory mechanisms might have operated. These possible mechanisms are discussed. Women suffering from the myopathy need not expect any deterioration during pregnancy.

Myophosphorylase deficiency (McArdle's disease) is a rare inherited myopathy characterized by symptoms of muscular fatigue and cramps during exercise, with occasional myoglobinuria (McArdle, 1951). Blood flowing from ischaemic muscle shows no rise in lactate levels, muscle biopsy examination reveals glycogen storage, and phosphorylase activity is absent. The administration of glucose and fructose often relieves muscle symptoms. Of the 40 patients whose cases have been recorded previously, only 10 have been female, and no affected individual has been studied during pregnancy.

\section{CASE REPORT}

A 21 year old woman with myophosphorylase deficiency who had previously been investigated fully (Cochrane, Hughes, Buxton, Yorke, 1973) was first referred to the Liverpool Maternity Hospital when 36 weeks pregnant because the patient and her general practitioner feared that severe muscle cramps might complicate labour, necessitating Caesarean section.

She had complained of muscular symptoms since early childhood. There had been no variation of these at different phases of the menstrual cycle, and during the pregnancy they were essentially unchanged. Muscular fatigue followed by cramps occurred on walking up inclines or several flights of stairs, and on riding a bicycle. The patient controlled her discomforts by gradual exercise and, after a short rest to recover from symptoms, found that she could walk a longer distance than before-that is, she experienced a 'second wind' phenomenon.
Occasional cramps in her hands were experienced while sewing and knitting, and she was occasionally awakened at night by similar symptoms. There was no history of passing dark urine which might have suggested myoglobinuria. The early stages of pregnancy had been uncomplicated.

The patient was $157 \mathrm{~cm}(5 \mathrm{ft} 2 \mathrm{in}$.) tall and she weighed $69 \mathrm{~kg}(152 \mathrm{lb}$.). No muscle wasting was present. Her blood pressure was $120 / 85 \mathrm{mmHg}$. The urine was normal in all respects and did not contain myoglobin. The uterus was enlarged to the size of a 36 weeks pregnancy. The foetal head was presenting and fitting well into the pelvic brim.

Investigations showed: haemoglobin $14.9 \mathrm{~g} /$ $100 \mathrm{ml}$; WBC $10,000 / \mathrm{cu}$. $\mathrm{mm}$; ESR $34 \mathrm{~mm}$ in one hour; blood glucose $80 \mathrm{mg} . / 100 \mathrm{ml}$; ; serum creatinine phosphokinase $51.7 \mu \mathrm{M} / \mathrm{min} / \mathrm{l}$. (normal range in adult female 3.3-61.7); serum lactate dehydrogenase $275 \mu \mathrm{M} / \mathrm{min} / \mathrm{l}$. (normal 70-240); the electrocardiograph was normal. The ischaemic lactate test was not performed, as this procedure was considered too painful at this stage of the pregnancy.

On the advice of Dr. B. McArdle, consultant chemical pathologist, Guy's Hospital, London, it was decided to await the spontaneous onset of labour in the expectation of normal delivery, although it was anticipated that the occurrence of severe muscle cramps might call for relief by the administration of glucose intravenously and epidural analgesia.

The patient was admitted to hospital in spontaneous labour at term. Initially the uterine contractions were irregular and infrequent. After 10 hours however they were occurring every five minutes and the uterine activity appeared to be entirely normal as judged by continuous recordings taken by an external 


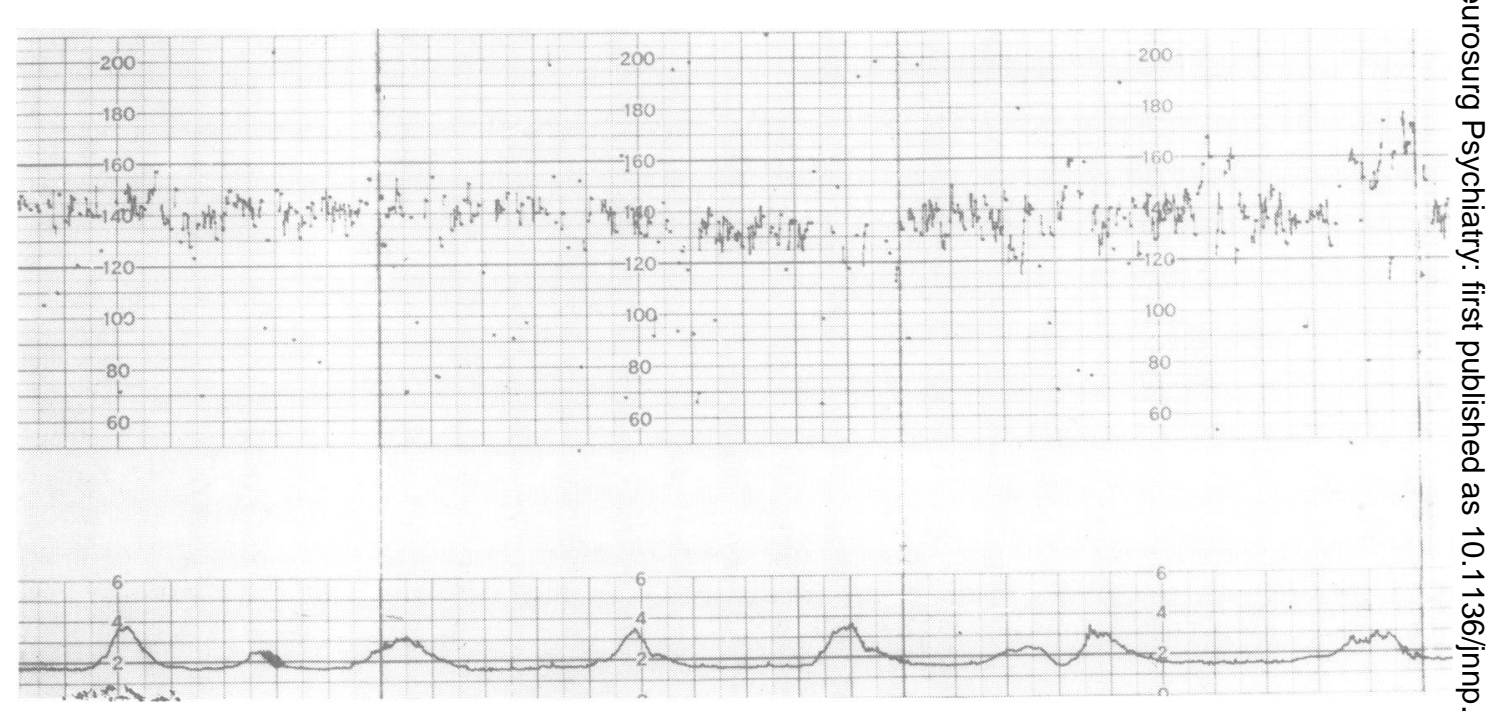

FIGURE A normal external cardiotocograph recording taken during the first stage of labour in a patient affected $d_{\sim}^{\infty}$ by myophosphorylase deficiency. Upper and lower tracings represent foetal heart rate and uterine contractionsin (1 cm/min) respectively.

cardiotocograph (Figure). So far, there had not been any interference by the attendants. At this stage, the forewaters were ruptured artificially and this was followed by an increase in the frequency of the contractions.

The patient's 'pains' had a reasonably normal distribution, being felt mainly in the back and lower abdomen. No abnormal muscle cramps were complained of. Her discomfort was relieved by lumbar epidural analgesia which was induced after 11 hours of labour. The foetal head presented in the occipitoposterior position, and after 18 hours of labour the uterine contractions remained short and ineffective. An intravenous infusion of $5 \%$ dextrose containing 0.5 units oxytocin in $500 \mathrm{ml}$. was therefore commenced. The first stage of labour was completed in 21 hours.

Progress in the second stage of labour was also slow, partly because of the lack of pushing reflex resulting from the epidural analgesia. Delivery was assisted with Keilland's forceps after a second stage lasting 45 minutes. The child was a living female infant weighing 3,200 $\mathrm{g}$ whose Apgar score was 10 after one minute. After delivery both mother and child made normal progress.

\section{COMMENT}

Pregnancies complicated by myopathies are very uncommon, and we have been unable to find any full description of pregnancy in a wom? suffering from myophosphorylase deficien Schmid and Hammaker (1961) described a $20 \mathrm{w}$ year old female with probable myophosphorylase deficiency, but no details of her single pregnancy? were given. Tobin and Coleman (1965) investigated a further two affected young females and commented that their reaction to future preg- $\frac{\mathbb{D}}{\Omega}$ nancies would be awaited with interest. Two affected sisters studied by Dawson, Spong, and 3 Harrington (1968) had one and four pregnancies? respectively. Again no details of the pregnancies? were given, although it was noted that the multi parous female suffered leg cramps and myo? globinuria after the delivery of her last baby? The case described here therefore appears to be the first of its kind to be reported fully.

The initial inefficiency of the uterine action during labour in this case is readily explained by? the occipito-posterior position of the presenting. part. The myophosphorylase deficiency did not appear to affect the uterine activity. In spite of the increased muscular effort expended, preg $N$ nancy and labour were normal and the musculaew symptoms of the underlying disease were un? changed. This suggests that compensators mechanisms might have operated. 
The administration of glucose and fructose is known to be associated with a reduction of muscular symptoms in the myopathy. In addition, an increase in muscle blood flow, and high arterial levels of free fatty acids (FFA) have similar beneficial effects (Pernow, Havel, and Jennings, 1967). During pregnancy, the metabolism of lipids and carbohydrate in the mother tends to become diabetic in character, fat providing a greater proportion of energy than does carbohydrate (Burt, 1960). The demands of the glycolytic system would therefore be expected to be reduced. A high plasma level of FFA results from increased mobilization from adipose tissue, possibly under the influence of human placental lactogen (Myant, 1970). The increase in muscle blood flow in pregnancy (Sinclair, 1963) may also alleviate symptoms. Finally, it is possible that an alternative glycolytic enzyme may come into play during pregnancy and labour.

The essential normality of uterine activity in the present report suggests that uterine smooth muscle phosphorylase is normal, supporting the finding of Engel, Eyerman, and Williams (1962) who noted normal phosphorylase activity in the smooth muscle of blood vessels in muscle of an affected patient.

The conclusion to be drawn from this one case is that women suffering from myophosphorylase deficiency need not expect any deterioration in their condition, or exacerbation of their symptoms during pregnancy.
We would like to thank Professor Sir Norman Jeffcoate and Dr. R. R. Hughes for permission to report this case and to express our appreciation to Dr. B. McArdle for helpful advice.

\section{REFERENCES}

Burt, R. L. (1960). Plasma nonesterified fatty acids in normal pregnancy and the puerperium. Obstetrics and Gynecology, 15, 460-464.

Cochrane, P., Hughes, R. R., Buxton, P. H., and Yorke, R. A. (1973). Myophosphorylase deficiency (McArdle's disease) in two interrelated families. Journal of Neurology, Neurosurgery, and Psychiatry, 36, 217-224.

Dawson, D. M., Spong, F. L., and Harrington, J. F. (1968). McArdle's disease: lack of muscle phosphorylase. Annals of Internal Medicine, 69, 229-235.

Engel, W. K., Eyerman, E. L., and Williams, H. E. (1962). Late-onset type of skeletal-muscle phosphorylase deficiency: a new familial variety with completely and partially affected subjects. New England Journal of Medicine, 268, $135-137$.

McArdle, B. (1951). Myopathy due to a defect in muscle glycogen breakdown. Clinical Science, 10, 13-35.

Myant, N. B. (1970). Lipid metabolism. In Scientific Foundations of Obstetrics and Gynaecology, p. 367. Edited by E. E. Philipp, J. Barnes, and M. Newton. Heinemann: London.

Pernow, B. B., Havel, R. J., and Jennings, D. B. (1967). The second wind phenomenon in McArdle's syndrome. Acta Medica Scandinavica. Suppl. 472, 294-307.

Schmid, R. and Hammaker, L. (1961). Hereditary absence of muscle phosphorylase (McArdle's syndrome). New England Journal of Medicine, 264, 223-225.

Sinclair, J. D. (1963). Cardiovascular changes during pregnancy. In Modern Trends in Human Reproductive Physiology-1, p. 182. Edited by H. M. Carey. Butterworths: London.

Tobin, R. B., and Coleman. W. A. (1965). A family study of phosphorylase deficiency in muscle. Annals of Internal Medicine, 62, 313-327. 